\title{
Changes in Traveler Stated Preference for Bus and Car Modes Due to Real-Time Schedule Information: A Conjoint Analysis
}

\author{
Thomas B. Reed \\ Jonathan C. Levine \\ University of Michigan
}

\section{Abstract}

This paper reports a conjoint analysis that explored potential impacts of real-time transit schedule information on mode preference. Conjoint analysis is a stated-preference approach to choice modeling in which respondents are asked to rate hypothetical products or services described by a single level of each of a number of attributes. Respondent ratings are decomposed into "part-worths" describing preferences for each attribute level. Subjects for the study were 500 randomly-sampled employees on the University of Michigan Medical Campus.

The conjoint data indicate potential significance of real-time transit schedule information for circumstances under which modal choice decisions are made on a day-today basis. Stated mode preference is not, however, significantly affected by availability of such information when decisions are made on a month-by-month basis. These results should further motivate transit system designers to provide such information, with particular attention paid to developing a highly accessible method of information dissemination. 


\section{Introduction}

Modal choice studies have consistently demonstrated that the disutility of wait time and other travel time spent out of the vehicle is greater than the disutility of in-vehicle travel time (Wilson 1967; Solomon et al. 1968; Henderson and Billheimer 1972; Stopher et al. 1974; Algers, Hansen and Tegnér 1975; Domencich and McFadden 1975; Heggie 1976; Wachs 1976; Hensher and Dalvi 1978; Cherlow 1981; Han 1987; Van Der Waard 1988). A number of factors̄ contribute to this difference in time cost, including uncertainty regarding the arrival of the vehicle, discomfort, and even differences in perception of the passage of time. Since the waits experienced by travelers differ by mode, with the duration of waits for public transit being significantly longer than those associated with travel via private automobile, the burden of wait time is a significant factor related to mode choice and remains a deterrent to selection of the transit mode.

Increasing traveler certainty regarding vehicle arrival times may allow adjustment of the traveler's own arrival time at the transit stop so as to minimize waits. Viewed in this fashion, the majority of the duration, and burden, of waits for transit may be a result of the traveler's uncertainty with respect to arrival of the transit vehicle. Many researchers have speculated that reduction in uncertainty of wait time associated with public transit would enhance the utility of transit to customers which in turn would lead to an increased customer base (Meads 1987; Fisher 1991; Le Squeren 1991; Blackledge and Pickup 1993; Clymer 1993; Federal Transit Administration 1993; Fisher and Ricketson 1994).

One approach that holds promise for reducing uncertainty, and the associated burden of out-of-vehicle travel time, is provision of real-time transit schedule information to inform travelers of when buses will actually arrive at a given location. Automatic Vehicle Location (AVL) and associated Advanced Public Transportation System (APTS) technologies make such information provision feasible. Recent European surveys of both travelers and transit service providers have, in fact, found information of various types to be quite important to the traveler (Pickup et al. 1990; Tarry and Pickup 1990; Blackledge and Pickup, 1993). Specifically, the surveys reported found that respondents viewed potential information systems as a mechanism to increase the convenience of public 
transit and improve the confidence of users. However, the potential of information provision as a means of reducing or eliminating traveler-perceived uncertainty with respect to transit operations has not been extensively studied.

The objective of the study reported here was to investigate the response of travelers (current and potential transit customers) to presentation of real-time transit schedule information, i.e., information that decreases traveler uncertainty with respect to arrival of the next transit vehicle. In particular, the study attempted to assess whether or not transit's mode share, as derived from a stated preference model, would, as many practitioners expect, increase as traveler certainty with respect to transit arrival time increases. If such effects are demonstrated, they might be the direct or indirect product of any number of effects: reduction in the duration of wait time; reduction in the disutility of a wait time of a given duration; greater certainty about arrival time; or other effects. This study made no attempt to distinguish between the various effects. However, a companion study did estimate the impact of transit arrival time information on the satisfaction and wait behavior of transit customers (Reed 1994).

The study divides modal choice decisions into two levels: the strategic level, in which modal choice decisions are made for the medium term of one month or more, and the tactical level, in which modal choice decisions are made on a dayto-day basis. The study did not show any effects of real-time schedule information on modal choice when decisions are made on a longer-term basis. In contrast, real-time schedule information may have significant impact on modal choice decisions made on a day-to-day basis. Transit managers interested in the potential of real-time schedule information to affect mode share would thus do well to seek ways in which longer-term modal choice decisions may be broken down into day-to-day decisions. These may include revisions in parking policy to encourage daily, rather than monthly or annual purchase of parking services, or the use of smart cards to eliminate fare payment barriers.

\section{Methodology}

Studies of modal choice typically come in two types: those based on revealed preference approaches, on the one hand, and stated preference, on the 
other. A revealed preference study could be used to forecast the mode-share impacts of a technology that is not yet implemented; for this to work, one would need to link the bundle of transportation service attributes represented by the technology (e.g., travel reliability, wait time reduction) to the set of variables included in the study. However, in the absence of a real-world implementation, a study in which respondents are presented with situations incorporating the technology and then asked for some indication of preference can also allow for such prediction; while these studies may lack some of the real-world behavioral basis of the revealed preferences, they can afford a potentially richer analysis into the impacts of a technology that has not yet been implemented.

Of the stated preference techniques, conjoint analysis has been used extensively as a means to evaluate individual preference or utility and has been used in many previous studies of travel behavior (Norman and Louviere 1974; Parker and Srinivasan 1976; Wind and Spitz 1976; Cherlow 1981; Louviere et al. 1981; Srinivasan et al. 1981; Rosko et al. 1985; Mackenzie 1992). In conjoint analysis, the researcher prepares a series of scenarios, situations, or products, each composed of a given level of each of a number of attributes. The researcher then presents these "bundles" of attributes to respondents and asks them to rate or rank each bundle (Elrod, Louviere and Davey 1992). Afterward, the scenario ratings are decomposed into "part-worths" for each attribute level. Part-worth scores can be computed on a common scale by regressing the rankings or ratings that subjects give to the alternative bundles and then normalizing the various regression results (SPSS 1990). Since the part-worth scores are all expressed in a common unit, they can, in principle, be added together to give a total rating for any combination of attributes. Therefore, the attribute part-worth scores can be used to reconstruct the original judgments or to predict choice among new combinations of attributes. Conjoint studies focus on individual or disaggregate responses, but estimation of aggregate response is also possible. The process of implementing a conjoint analysis is well documented (Green 1974; Kocur et al. 1982; Louviere 1984; Tull and Hawkins 1987; Louviere 1988; Hair et al. 1992). 


\section{Implementation}

The study described here, designed to explore potential mode share effects of real-time transit information, was implemented in Spring 1994 in the form of a mail-out conjoint analysis among employees of the University of Michigan Medical Campus. The study population was chosen because of the opportunity to cooperate with, and gain support from, a concurrent Medical Campus transit pilot project of the Ann Arbor Transportation Authority (AATA) and the University of Michigan Parking Operations. The study is retrospective in that subjects were asked to rate hypothetical situations that had ostensibly already occurred. An assumption underlying the study is that processes of modal choice may differ between short term, day-to-day modal choices, on the one hand, and longer-term choices, such as those that might occur with decisions to purchase a bus pass or parking permit, on the other. Since strategic (long term) and tactical (day-to-day) decisions are likely to be separate, though related, the study was divided into two parallel portions. For each segment, the travel scenario attributes and levels to be tested were first developed, and then the conjoint analysis instrument was prepared and disseminated.

\section{Travel Scenario Attributes}

Conjoint analysis is based upon the delineation of a limited set of attributes, together with two or more possible values for each attribute. The attributes included in the study of strategic mode choice are presented in the top portion of Table 1. The parking fee levels correspond roughly to the current fee on the Medical Campus and an amount twice that fee. The bus fare levels are $\$ 25$ per month (the current one-way fare) and free. The walk from home to the bus stop, time once in the vehicle, and bus arrival reliability were intended to approximate conditions faced by many within the service area of the Ann Arbor Transportation Authority. The levels for the "bus arrival information format" attribute were selected as representative of the status quo (printed format) and a telephonebased information system that could potentially be implemented. The attribute "bus information" and its impact on behavior under different levels of bus service reliability are the primary focus of study. 


\section{Table 1 \\ Attributes Presènted in the Mode Choice Studies}

\begin{tabular}{|c|c|c|}
\hline Mode & Attribute & Level \\
\hline \multicolumn{3}{|c|}{ Strategic Study } \\
\hline $\mathrm{Car}$ & Parking Fee & $\begin{array}{l}\text { 1: } \$ 30 / \text { month } \\
2: \$ 60 / \text { month }\end{array}$ \\
\hline Bus & Fare & $\begin{array}{l}\text { 1: Free } \\
2: \$ 25 / \text { month }\end{array}$ \\
\hline Bus & Walk: Home to Bus Stop ${ }^{a}$ & $\begin{array}{l}\text { 1: } 1 \text { block } \\
2: 3 \text { blocks }\end{array}$ \\
\hline Both & $\begin{array}{l}\text { Time Once in Vehicle } \\
\text { (scheduled bus arrival) }\end{array}$ & $\begin{array}{l}\text { 1: Car: } 10 \text { mins; Bus: } 15 \text { mins (7:40am) } \\
\text { 2: Car: } 20 \text { mins; Bus: } 30 \text { mins (7:25am) }\end{array}$ \\
\hline Bus & Arrival Reliability ${ }^{b}$ & $\begin{array}{l}\text { 1: Always comes on time } \\
\text { 2: Comes } 5 \text { mins late half the time }\end{array}$ \\
\hline Bus & Arrival Information Format & $\begin{array}{l}\text { 1: Printed schedule of bus arrival times; } \\
\text { in the traveler's hands }\end{array}$ \\
\hline & & $\begin{array}{l}\text { 2: Actual arrival time of the next bus; } \\
\text { provided via a phone recording }\end{array}$ \\
\hline $\begin{array}{l}\text { Tactic: } \\
\text { Car }\end{array}$ & $\begin{array}{l}\text { tudy } \\
\text { Parking Fee }\end{array}$ & $\begin{array}{l}1: \$ 6 / \text { day } \\
2: \$ 12 / \text { day }\end{array}$ \\
\hline Bus & Fare & $\begin{array}{l}\text { 1: Free } \\
2: \$ 1.50 / \text { day }\end{array}$ \\
\hline Bus & Walk: Home to Bus Stop ${ }^{a}$ & $\begin{array}{l}\text { 1: } 1 \text { block } \\
\text { 2: } 3 \text { blocks }\end{array}$ \\
\hline Both & $\begin{array}{l}\text { Time Once in Vehicle } \\
\text { (scheduled bus arrival) }\end{array}$ & $\begin{array}{l}\text { 1: Car: } 10 \text { mins; Bus: } 15 \text { mins ( } 7: 40 \mathrm{am}) \\
\text { 2: Car: } 20 \text { mins; Bus: } 30 \text { mins (7:25am) }\end{array}$ \\
\hline Bus & $\begin{array}{l}\text { Arrival Status } \\
\text { (source; information) }\end{array}$ & $\begin{array}{l}\text { 1: Printed schedule of bus arrival times } \\
\text { only: actual status unknown } \\
\text { 2: Actual arrival time of next bus; provid- } \\
\text { ed via phone recording: bus on time } \\
\text { 3: Actual arrival time of next bus; provid- } \\
\text { ed via phone recording: bus } 5 \text { mins late }\end{array}$ \\
\hline
\end{tabular}

" Walk to Stop (work end) is one block (a bus stop is just outside your place of work).

${ }^{\circ}$ Buses are never early in this study.

'No bus leaves the stop before the scheduled time. 
The attributes included in the study of tactical mode choice are presented in the bottom portion of Table 1. The parking fee, bus fare, walk to bus stop, and time once in vehicle take on values similar to the analogous attributes in the strategic study, but are stated on a daily rather than monthly basis. The tactical study differs from the strategic, in that the actual status of the bus is known in the former but not the latter. Therefore, in place of the "bus arrival reliability" and "bus arrival information format" attributes of the strategic study, each situation for the tactical study includes one of three types of actual bus arrival status information: either only a printed schedule of bus arrival times such that actual bus arrival status is unknown; or a phone recording providing the actual arrival time of the next bus, with the bus on time; or a phone recording providing the actual arrival time of the next bus, with the bus five minutes late. As in the strategic study, the attribute "bus information" is the primary focus of study.

The goal in selecting attributes for the conjoint analysis was not complete description of the determinants of the modal choice decision, but rather a depiction of potential transit and auto trips sufficient to enable the respondent to react meaningfully to the alternatives. The number of attributes and levels was restricted to the small set shown in each case for two reasons. First, the given attributes were assumed to represent the most important issues in mode-choice behavior. Second, the attributes included in a conjoint analysis must be as few as possible, while still offering an adequate description of alternatives, because conjoint analysis constructs alternatives from combinations of attributes; each attribute greatly increases the number of scenarios that need to be developed, which, in turn, raises the danger of overwhelming the cognitive capacities of respondents. For example, gasoline price, conceivably an important factor, was not included as an attribute in the analysis. To the extent that travelers are aware of the true costs of driving, changes in the price of gas should have an effect similar to changes in the parking fee. Headway and transport-time variance also were not included as attributes in the analysis and were assumed to have zero variance. These assumptions do not eliminate the potential value of real-time schedule information, however, because bus arrival time can be uncertain even if headway 
and transport-time exhibit zero wariance. Such a situation would arise if the system is operating at a time offset from the schedule that was unknown to the customer. To the contrary, the assumptions of zero variance in headway and transport time are likely to result in an underestimation of the value that information would have in actual practice, since the increment of uncertainty that is removable through information provision would grow with service variance.

\section{Conjoint Analysis Instruments}

The levels for the attributes chosen for the strategic and tactical designs can be combined into 64 and 48 possible situations, respectively. A single conjoint study with such a large number of situations would likely not be effective in a low-motivation situation such as responding to a mail survey, because such an instrument, due to the burden it would place on respondents, would be unlikely to elicit data sufficient either in quantity or quality. Fortunately, fractional-factorial designs are available that reduce the number of conjoint situations required, at the expense of the ability to detect some or all interaction effects. The simplest fractional-factorial design is a "main effects" plan, from which no interactions can be determined. Although significant nonlinearities in preference for transit attributes, or interactions among attributes, undoubtedly do exist, specific mode share effects were not the main focus of the study and so the loss of the ability to detect interactions was deemed an acceptable cost of improving the potential quality and quantity of data obtained. The supposition that a conjoint instrument designed to capture interactions would degrade data quality is supported by the fact that participants reported difficulty responding to just such an instrument during pilot testing.

Fractional-factorial-based conjoint designs for studies involving few attributes are readily available in published tables; selection among alternative designs is made on the basis of number of attributes and requirements for detection of nonlinearities or interaction effects. The conjoint analysis design for the strategic mode choice study was patterned after the main-effects design of Plan $5 \mathrm{a}$ in Kocur et al. (1982). A conjoint analysis design patterned after Plan 58a in Kocur et al. (1982) was chosen for the tactical mode choice study. These designs, 


\begin{tabular}{|c|c|c|c|c|c|c|}
\hline \multicolumn{7}{|c|}{$\begin{array}{l}\text { Table } 2 \\
\text { Travel Situations in the Mode-Choice Study Designs }\end{array}$} \\
\hline Card\# & $\begin{array}{l}\text { Parking } \\
\text { Fee }\end{array}$ & $\begin{array}{l}\text { Bus } \\
\text { Fare }\end{array}$ & $\begin{array}{l}\text { Walk to } \\
\text { Bus }\end{array}$ & $\begin{array}{l}\text { Travel } \\
\text { Times }\end{array}$ & $\begin{array}{c}\text { Bus } \\
\text { Reliability }\end{array}$ & $\begin{array}{l}\text { Bus Info } \\
\text { Format }\end{array}$ \\
\hline \multicolumn{7}{|c|}{ Strategic Study } \\
\hline 1 & 1 & 1 & 1 & 1 & 1 & 1 \\
\hline 2 & 1 & 1 & 2 & 2 & 1 & 2 \\
\hline 3 & 1 & 2 & 1 & 2 & 2 & 1 \\
\hline 4 & 1 & 2 & 2 & 1 & 2 & 2 \\
\hline 5 & 2 & 2 & 2 & 2 & 1 & 1 \\
\hline 6 & 2 & 2 & 1 & 1 & 1 & 2 \\
\hline 7 & 2 & 1 & 2 & 1 & 2 & 1 \\
\hline 8 & 2 & 1 & 1 & 2 & 2 & 2 \\
\hline Card \# & $\begin{array}{l}\text { Parking } \\
\text { Fee }\end{array}$ & $\begin{array}{l}\text { Bus } \\
\text { Fare }\end{array}$ & $\begin{array}{l}\text { Walk to } \\
\text { Bus }\end{array}$ & $\begin{array}{l}\text { Travel } \\
\text { Times }\end{array}$ & $\begin{array}{l}\text { Bus Status } \\
\quad \text { Info }\end{array}$ & \\
\hline \multicolumn{7}{|c|}{ Tactical Study } \\
\hline 1 & 1 & 1 & 1 & 1 & 1 & \\
\hline 2 & 2 & 2 & 2 & 2 & 1 & \\
\hline 3 & 2 & 2 & 1 & 1 & 2 & \\
\hline 4 & 1 & 1 & 2 & 2 & 2 & \\
\hline 5 & 2 & 1 & 2 & 1 & 3 & \\
\hline 6 & 1 & 2 & 1 & 2 & 3 & \\
\hline 7 & 1 & 2 & 2 & 1 & 2 & \\
\hline 8 & 2 & 1 & 1 & 2 & 2 & \\
\hline
\end{tabular}

which each require eight cards (bundles of attributes), are shown in Table 2. It is important to note that main-effects designs, which are based upon the assumption of no interaction between factors, cannot guarantee independence of the main effects from interaction effects. Indeed, the assumption of no interaction guarantees that no interaction will be found.

To provide a consistent basis for comparison of responses and development of models, prior to rating the scenarios respondents were instructed to imagine themselves in a single hypothetical scenario instead of in their own real-life situation. In the strategic mode-choice study, respondents were asked to: 
Imagine that it is the first of the month and you are at your home considering your choices for commuting between home and work. You must decide to drive alone or take a bus. Since parking permits and bus passes are purchased on a monthly basis, your decision will affect your travel plans for the entire month. Imagine also that you know the bus you need is scheduled to come every 15 minutes (at 7:25, 7:40, 7:55, and so on) to a bus stop near your home. The bus also stops just outside your place of work. You must be at work by 8:00 a.m.

In the tactical mode-choice study, respondents were asked to:

Imagine that you are at your home and getting ready to go to work. You need to be at work by 8:00 a.m. and must decide to drive alone or take a bus. Since parking permits and bus passes are purchased on a daily basis, you are faced with this task each morning. Imagine also that you know the bus you need is scheduled to come every 15 minutes (at 7:25, 7:40, 7:55, and so on) to a bus stop near your home. The bus also stops just outside your place of work. The bus is on time half of the time and 5 minutes late the other half of the time.

Examples of the conjoint cards for the strategic and tactical studies are shown in Figure 1. As evident from the cards, a full-concept method, in contrast to a two-factor-at-a-time or paired trade-off method, was used in each case. That is, respondents were asked to rate situations that are defined by given levels of all attributes presented simultaneously. Moreover, to compensate for potential bias, three sets of conjoint cards were prepared and distributed to respondents on a random basis; all cards contained identical information but were presented in different sequences. The primary data for the study consists of the ratings of the eight situations produced by the respondents.

\section{Dissemination of the Conjoint Instruments}

As shown in Table 3, a random sample of 2,000 potential participants was drawn from the more than 12,000 employees affiliated with the Medical Cam- 


\section{[Strategic] Situation 1}

\begin{tabular}{ll}
\hline Parking Fee: & $\$ 30 /$ month \\
Bus Fare: & Free \\
Walk to Stop: & 1 block \\
Time Once in Vehicle-Car: & 10 mins; Bus: 15 mins \\
Bus Reliability: & Always comes on time (7:40 a.m.) \\
Bus Information: & A printed schedule of bus arrival times
\end{tabular}

Given this situation, how likely are you to drive alone or take a bus to work this month?

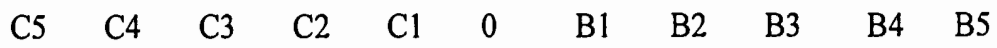
(Drive Alone)
(circle a number)
(Take Bus)

\section{[Tactical] Situation 1}

Parking Fee:

Bus Fare:

Walk to Stop:

Time Once in Vehicle-Car:

\section{$\$ 6 /$ day}

Free

1 block

10 mins; Bus: 15 mins

It is 7:37 a.m. The bus is scheduled to come at 7:40. You have only the printed bus schedule. Thus, you do not know if the bus will come on time (in 3 mins, at 7:40) or come 5 mins late (in $8 \mathrm{~min}$, at 7:45).

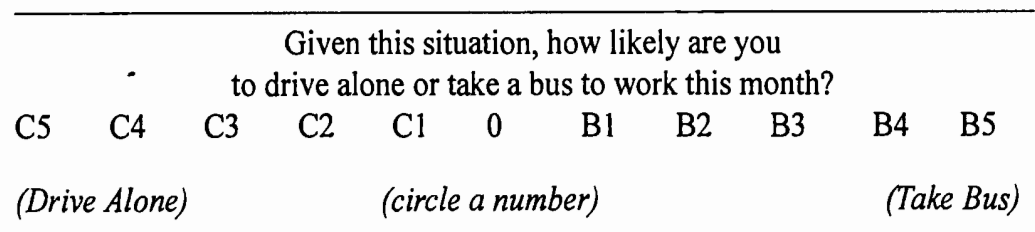

Figure 1. Example situation cards used in the mode choice studies. 
pus. After cases with inappropriate or unusable addresses were deleted, 500 participants were randomly selected and divided into the two subgroups, 250 per group. Inappropriate cases were considered to be employees with work addresses not on the Medical Campus, employees with a Medical Campus address or post office box for Table 3 the Survey Response Information

\begin{tabular}{lrr}
\hline & $\begin{array}{r}\text { Strategic } \\
\text { Study }\end{array}$ & $\begin{array}{r}\text { Tactical } \\
\text { Study }\end{array}$ \\
\hline Population & $\sim 12,000$ & $-\sim 12,000$ \\
Original Sample & 250 & 250 \\
Invalid Addresses & 12 & 12 \\
Original Sample Augmented by & 12 & 12 \\
Left University Employment & 4 & 3 \\
Net Sample Size & 246 & 247 \\
Unusable Responses & 13 & 19 \\
Usable Responses & 65 & 65 \\
Usable Response Rate & $26.4 \%$ & $26.3 \%$
\end{tabular}
home address, and employees who could not possibly commute on a daily basis from the home address given, e.g., a home address in California. Different participants were involved in the two studies to reduce the burden on each respondent and therefore increase the response rate.

The conjoint materials were mailed via U.S. bulk mail to the home address of each employee chosen. A reminder postcard, with first-class postage, was mailed after a couple of weeks to those who had not yet responded, and a second survey packet was mailed by bulk mail a couple of weeks after that to those who had still not responded. Responding to the survey required approximately 10-15 minutes of a participant's time, and so the response rate was anticipated to be low. To boost the response rate, potential respondents were informed that the names of those returning the survey would be entered in a random drawing for a $\$ 50$ gift of appreciation. At the same time that the gift was awarded, a post card expressing gratitude for participation was mailed to all respondents. The overall effective response rate from the two mailings and postcard, shown in Table 3, was 65 of 246 , or 26.4 percent, for the strategic portion and 65 of 247 , or 26.3 percent, for the tactical portion. 


\section{Conjoint Model}

A primary goal of the study was to develop a model to describe the ratings that respondents give the various transit situations. The model assumed in this study was linear and additive, as described in

$$
\text { Situation Rating }=a_{0}+\sum_{\mathrm{i}=1}^{\mathrm{I}} \sum_{\mathrm{j}=1}^{\mathrm{J}} a_{i j} A_{i j}
$$

where $a_{0}$ is a constant; $a_{i j}$ represents the coefficient for level $j$ of attribute $i$; and $A_{i j}$ represents a dummy variable that takes a value of 1 if level $j$ of attribute $i$ is included in the scenario under inspection and takes a value of 0 otherwise. The potential spread of the derived product rating depends on the range of the coefficients (part-worths), which can be controlled by the conjoint design, and can include both positive and negative values. This model can produce a composite rating associated with a transit situation on either the individual or aggregate level; aggregate part-worths represent the mean of the corresponding part-worths from the models from each individual respondent.

In this study, part-worths for a model specific to each respondent were estimated by decomposing the ratings of the eight transit situations produced by each respondent (SPSS 1990). The individual-specific part-worths were then averaged both for descriptive purposes and to explore any overall trends or processes that may be affecting modal preference. The average part-worths from the strategic and tactical models are presented in the top and bottom portions of Table 4, respectively. Table 4 also presents a measure of the "importance" of each attribute, which can be interpreted as an index of the contribution of a given factor to the overall modal choice decision; since the part-worths are expressed on a common scale, the attributes can be compared by taking the part-worth range for each attribute and dividing it by the sum of all the part-worth ranges to compute these "importance" scores.

Statistical significance of the averaged part-worths in each study was estimated by treating the part-worths of each of the 65 subjects as individual obser- 


\section{Table 4}

Averaged Conjoint Model Part-worths for the Mode Choice Studies

\begin{tabular}{|c|c|c|c|c|c|}
\hline Attribute & $\begin{array}{l}\text { Attribute } \\
\text { Importance }\end{array}$ & $\begin{array}{l}\text { Attribute } \\
\text { Level }\end{array}$ & $\begin{array}{l}\text { Part- } \\
\text { worth }\end{array}$ & $\begin{array}{c}t- \\
\text { value }\end{array}$ & $\begin{array}{l}\text { 2-Tail } \\
\text { Sig. }^{c}\end{array}$ \\
\hline $\begin{array}{l}\text { Strategic St } \\
\text { Parking Fee }\end{array}$ & $\begin{array}{c}\text { dy }(n=65) \\
22.0\end{array}$ & $\begin{array}{l}\$ 30 / \text { month } \\
\$ 60 / \text { month }\end{array}$ & $\begin{array}{r}-0.96 \\
0.96\end{array}$ & $\begin{array}{r}-8.09 \\
8.09\end{array}$ & $\begin{array}{l}0.000 \\
0.000\end{array}$ \\
\hline Bus Fare & 34.9 & $\begin{array}{l}\text { Free } \\
\$ 25 / \text { month }\end{array}$ & $\begin{array}{r}1.52 \\
-1.52\end{array}$ & $\begin{array}{r}10.72 \\
-10.72\end{array}$ & $\begin{array}{l}0.000 \\
0.000\end{array}$ \\
\hline $\begin{array}{l}\text { Walk: Home } \\
\text { to Bus Stop }\end{array}$ & 12.1 & $\begin{array}{l}1 \text { block } \\
3 \text { blocks }\end{array}$ & $\begin{array}{r}0.53 \\
-0.53\end{array}$ & $\begin{array}{r}6.83 \\
-6.83\end{array}$ & $\begin{array}{l}0.000 \\
0.000\end{array}$ \\
\hline $\begin{array}{l}\text { Time Once } \\
\text { in Vehicle }\end{array}$ & 9.2 & $\begin{array}{l}\text { Car: } 10 \text { min; Bus: } 15 \\
\text { Car: } 20 \text { min; Bus: } 30\end{array}$ & $\begin{array}{r}0.40 \\
-0.40\end{array}$ & $\begin{array}{r}4.10 \\
-4.10\end{array}$ & $\begin{array}{l}0.000 \\
0.000\end{array}$ \\
\hline $\begin{array}{l}\text { Bus } \\
\text { Reliability }\end{array}$ & 19.0 & $\begin{array}{l}\text { Always on time; } \\
5 \text { min late half time }\end{array}$ & $\begin{array}{r}0.83 \\
-0.83\end{array}$ & $\begin{array}{r}5.99 \\
-5.99\end{array}$ & $\begin{array}{l}0.000 \\
0.000\end{array}$ \\
\hline $\begin{array}{l}\text { Bus Info } \\
\text { Format }\end{array}$ & 2.8 & $\begin{array}{l}\text { Print } \\
\text { Phone }\end{array}$ & $\begin{array}{r}0.12 \\
-0.12\end{array}$ & $\begin{array}{r}1.70 \\
-1.70\end{array}$ & $\begin{array}{r}0.095 \\
-0.095\end{array}$ \\
\hline Constant & & & 5.17 & 0.65 & 0.518 \\
\hline Pearson's R & & & 1.000 & & 0.000 \\
\hline $\begin{array}{l}\text { Tactical Stu } \\
\text { Parking Fee }\end{array}$ & $\begin{array}{r}y(n=65) \\
35.9\end{array}$ & $\begin{array}{l}\$ 6 / \text { day } \\
\$ 12 / \text { day }\end{array}$ & $\begin{array}{r}-0.87 \\
0.87\end{array}$ & $\begin{array}{r}-6.39 \\
6.39\end{array}$ & $\begin{array}{l}0.000 \\
0.000\end{array}$ \\
\hline Bus Fare & 8.4 & $\begin{array}{l}\text { Free } \\
\$ 1.50 / \text { day }\end{array}$ & $\begin{array}{r}0.20 \\
-0.20\end{array}$ & $\begin{array}{r}2.43 \\
-2.43\end{array}$ & $\begin{array}{l}0.018 \\
0.018\end{array}$ \\
\hline $\begin{array}{l}\text { Walk: Home } \\
\text { to Bus Stop }\end{array}$ & 31.3 & $\begin{array}{l}1 \text { block } \\
3 \text { blocks }\end{array}$ & $\begin{array}{r}0.76 \\
-0.76\end{array}$ & $\begin{array}{r}6.59 \\
-6.59\end{array}$ & $\begin{array}{l}0.000 \\
0.000\end{array}$ \\
\hline $\begin{array}{l}\text { Time Once } \\
\text { in Vehicle }\end{array}$ & 1.9 & $\begin{array}{l}\text { Car: } 10 \text { min; Bus: } 15 \\
\text { Car: } 20 \text { min; Bus: } 30\end{array}$ & $\begin{array}{r}-0.05 \\
0.05\end{array}$ & $\begin{array}{r}-0.44 \\
0.44\end{array}$ & $\begin{array}{l}0.659 \\
0.659\end{array}$ \\
\hline $\begin{array}{l}\text { Bus Arrival } \\
\text { Status }\end{array}$ & 22.5 & $\begin{array}{l}\text { Print; no information } \\
\text { Phone; bus on time } \\
\text { Phone; bus } 5 \text { min late }\end{array}$ & $\begin{array}{r}-0.65 \\
0.21 \\
0.44\end{array}$ & $\begin{array}{r}-3.11 \\
1.04 \\
1.82\end{array}$ & $\begin{array}{l}0.003 \\
0.300 \\
0.073\end{array}$ \\
\hline Constant & & & 6.19 & 4.23 & 0.000 \\
\hline Pearson's R & & & 0.992 & & 0.000 \\
\hline
\end{tabular}


vations; the mean of these observations was tested against the null hypothesis that the population mean is equal to zero $(n=65)$. The alternative view is that each observation is subject to a sampling error because of the random component of an individuals' responses to the conjoint experiment. This view would necessitate a correction in the significance calculations reported in Table 4. Thus, reliance on significance calculations reported in Table 4 is based on a view of each of individual part-worths as not being subject to sampling error.

To further gauge the appropriateness of the aggregation procedure, individuals' ratings of cards were "predicted" ex post facto on the basis of aggregate part-worths; the $\mathrm{R}$ statistic reported is the correlation between actual and predicted ratings. The high levels of the $\mathrm{R}$ statistic seen for each model indicates a high degree of reliability of the aggregation procedure.

Positive part-worths in Table 4 are interpreted as contributing to a choice of bus; negative part-worths contribute to a higher rating for the automobile. Inspection of the aggregate part-worths for the strategic study, shown in the top portion of Table 4, reveals a number of expected results; selection of the bus mode is associated with higher auto parking costs, lower bus fares, shorter walks to the bus stop, and greater bus reliability. A somewhat less intuitive, but not unreasonable result, is that preference for the automobile mode increased with in-vehicle time. Finally, although the results for bus information appear contrary to expectations (the part-worth for the attribute representing availability of realtime schedule information via phone is lower than the part-worth representing availability of only the printed schedule), the data show that the information attribute in the strategic study is not statistically significant, and so the counterintuitive sign is meaningless. Most relevant to this study, the importance scores show that bus-arrival information was not important to the respondents in a strategic mode-choice situation, as it accounted for under 3 percent of the total range of part-worths.

The data thus do not support the hypothesis that transit information will increase transit mode share on a month-to-month-basis. Apparently, the difference between obtaining schedule information via print and via the phone is not useful when planning for the longer term. (This is, of course, not to imply that 
information itself is not important, as the study tested only the difference in the medium for presentation of the information.) The most important attributes in strategic mode choice, in order, are seen to be bus fare, parking fee, and bus reliability. It should be emphasized that these relative weights are specific to the scenarios tested and may not be generally applicable. In particular, the prominence of bus fare in this study might be somewhat due to the special case tested, i.e., people may respond with disproportionate favor to "free" service.

The aggregate part-worths for the tactical study, shown in the bottom portion of Table 4, reveal many of the same relationships evident in the strategic study between transportation characteristics and mode choice; these effects include those of parking charges, bus fares, and walking distance. The part-worths for "time once in vehicle" appear to contradict the results of the strategic study; however, the data show that this attribute in the tactical study is not statistically significant and so the ostensible contradiction is inconclusive. Most importantly to this study, phone information is preferred to the printed schedule only, and the "importance" statistic places information provision in this context among the more important mode share determinants, accounting for about 23 percent of the total range of part-worth scores. In this study, phone information appears to be of greater value when the bus is late than it is when the bus is on time. A number of arguments could be made either way; however, this result might also simply be an artifact of the study presentation. Regardless, in the tactical study, situations in which real-time schedule information is provided receive higher scores, without exception, than situations in which only the printed bus schedule is given.

The data then appear to support the hypotheses that real-time schedule information increases the rating, given the bus mode when decisions are made on a day-to-day basis. The most important attributes in tactical mode choice, in order, are seen to be parking fee, walk from home to the bus stop, and bus-status information. Moreover, situations in which real-time schedule information is provided are preferred to situations in which only the printed bus schedule is given. Bus fare and time once in the vehicle were relatively unimportant in the decisions of respondents. 


\section{Conjoint Analysis in Transportation Preference Studies}

Two methodological lessons about use of conjoint analysis in modal choice studies were learned from this study: 1) the conjoint method is difficult to use with a mail-out approach of surveying, and 2) conjoint analysis has disadvantages arising from its marketing heritage. Much research into transportation behavior relies on use of a mail-out approach, such as used in this study. However, the experience of this study suggests that lack of direct interaction with respondents has the potential to limit significantly the quality of data obtained through a conjoint analysis, as individual respondents might differ significantly in their interpretation of the task requested of them. This disadvantage is experienced by all surveys, of course. However, the complexity of the conjoint method and the "newness" of the method to respondents makes conjoint analysis especially vulnerable to misunderstandings. Implementing the study in a face-to-face manner could have allowed the material to be better explained to potential respondents and thereby circumvented some of these data quality concerns. However, faceto-face interviewing is not possible in many studies due to resource constraints. In this study in particular, many difficulties would have been involved in contacting and setting up interviews with potential respondents on the Medical Campus. As a result, for this study at least, the mail-out format was thought to be more effective overall. Pictographs, instead of wording, representing the attributes used in the study might have reduced some of the misunderstandings due to the mailout format.

Perhaps the most significant limitation of conjoint analysis is the marketing heritage of the methodology, which presents some interesting challenges to use of this technique in the study of travel behavior and in application of conjoint results to development of transportation systems. Marketing studies are typically concerned with market share and so use the individual as basis for data analysis. Travel behavior studies are also interested in the response of individuals and in market share, but are also faced with the task of providing results that transit authorities can use in systems design. When the data from a conjoint study indicates that a number of clusters of similarly-minded potential customers exists within a target population, marketers can easily develop a collection of prod: 
ucts- such as breakfast cereals - that cater to the subgroups of customers. Transportation information systems' $\$$ an also be developed with a variety of user interfaces. However, resource constraints severely limit the number and variety of functions that can be included in any systems design. That is, in gross simplification, any number of types of breakfast cereal can be developed, and so most all people can be satisfied, but the number of basic transit system alternatives that can be implemented is strictly limited, and so more than a few potential customers will likely be left less than satisfied. In this sense, the conjoint analysis methodology cannot be easily adapted to the transportation context, where consensus building is critical to success. A potential approach to circumventing the difficulty just described is to combine conjoint analysis with social decision analysis; such a combination holds great potential for systems-design and consensus-building efforts and should be further investigated.

While acknowledging the above-mentioned drawbacks of using conjoint in studies of this type, a primary advantage of the method is that, inasmuch as the conjoint analysis approach does not rely on the existence of any technology, the technique can be utilized to explore the effectiveness of, and evaluate traveler response to, alternative emerging traveler information services, under various conditions of transit headway, variance, and so on, prior to implementation. Furthermore, "satisfaction" and mode share estimates from conjoint analysis, combined with systems costs, can be used to guide decisionmaking regarding the adoption or rejection of traveler information services, i.e., as a type of pre-deployment analysis methodology. Conjoint methodologies can thus serve as background for actual transit implementations, as well as for further study aimed at determining changes in transit-use behavior due to improvements in transit operations, customer information, parking policy, or other system characteristics.

\section{Implications for Transit System Improvement}

Because the sample population of employees for this study was drawn locally, inferences are specific to the service area of the Ann Arbor Transportation Authority and to the University of Michigan Medical Campus. However, to a significant degree, the scenarios presented do represent the real living situation 
of a number of people within the service area of the Ann Arbor Transportation Authority, which could be said to be similar to the service provided in many suburban areas. Sixty percent of the people in the original representative sample taken from the Medical Campus employee database live within the AATA service area, as defined by postal ZIP codes. However, the AATA service area, in terms of postal ZIP codes, is much broader than the hypothetical scenarios presented for a variety of reasons. People may not have good access to an AATA bus route, for example. Similarly, many would have to transfer buses if they were to use AATA service. Thus, it may be that a majority of people do not live under conditions similar to those in the hypothetical scenarios.

Nonetheless, the finding that real-time schedule information may be much more significant to tactical (i.e., day-to-day) than strategic (i.e., long term) modal choice decisions may have broader applicability. Transit districts implementing technologies for the dissemination of real-time schedule information will need to combine these technologies with other programs to lead to changes in modal decisions by people who are not current bus customers. The mode of information dissemination is particularly important; if a great share of the impact of real-time schedule information is on day-to-day-hence, perhaps more impulsive-decisions, the method used to disseminate the information becomes critical. It may be that television and kiosk modes of information delivery, requiring less action on the part of the traveler are superior to the telephone-based information supposed here. In fact, an experiment executed in conjunction with this study, in which a trial real-time information service was set up by telephone, generated a very low volume of calls (Reed 1994). Perhaps most significantly, real-time schedule information may have the greatest mode share impact when its provision is accompanied by programs to encourage flexible, modal decisionmaking. An example of such a policy would be the replacement of monthly or annual parking fees with hourly or daily fees. These changes could be further augmented through the use of smart cards that would be valid for both parking payment and bus fares. 
In sum, the fact that the rating that respondents give to public transit increases with provision of rear-time transit schedule information, at least when travel decisions are made on a day-to-day basis and under the hypothetical conditions presented in this study, should further motivate transit system designers to redouble efforts to investigate such information. This is especially true since information should not only reduce the burden of a given wait but also reduce the duration of the wait.

\section{Acknowledgment}

The authors are indebted to the Ann Arbor Transportation Authority and the Great Lakes Center for Truck and Transit Research of the University of Michigan, both in Ann Arbor, Michigan, for funding and other support in undertaking this study.

\section{References}

Algers, S., S. Hansen, and G. Tegnér. 1975. Role of Waiting Time, Comfort, and Convenience in Modal Choice for Work Trip. Transportation Research Record 534:38-51. Blackledge, D.A. and L. Pickup. 1993. Public Transport Passenger Information SystemsThe Potential of Advanced Transport Telematics. Proceedings of the 3rd Annual Meeting of IVHS AMERICA: 295-301.

Cherlow, J.R. 1981. Measuring Values of Travel Time Savings. Journal of Consumer Research 7 (March): 360-371.

Clymer, B. 1993. Transit Initiatives in IVHS. IVHS Review, Spring: 35-44.

Domencich, T.A. and D. McFadden, 1975. Urban Travel Demand Analysis. North Holland, Amsterdam.

Elrod, T., J. J. Louviere, and K. S. Davey. 1992. An Empirical Comparison of RatingsBased and Choice-Based Conjoint Models. Journal of Marketing Research, Vol. 29: 368-77.

Federal Transit Administration 1993. Report on the Advanced Public Transportation Systems Smart Systems Integration Workshop, San Francisco, California, August 18, 1992. Prepared at the University of Michigan, in conjunction with the Ann Arbor Transportation Authority, for the Federal Transit Administration, U.S. Department of Transportation, Washington, D.C.

Fisher, R. J. 1991. Smart Travelers of the 1990s. ITE Journal, Institute of Transportation Engineers, January: 17-19. 
Fisher, R. J., and S. Ricketson. 1994. The Transit Opportunity in IVHS. Federal Transit Administration, Washington, D.C.

Green, P. E. 1974. On the Design of Choice Experiments Involving Multifactor Alternatives. Journal of Consumer Research 1 (September): 61-68.

Hair, J. F., Jr., R. E. Anderson, R. L. Tatham, and W. C. Black. 1992. Conjoint Analysis. Chapter 9 in Multivariate Data Analysis with Readings. New York: Macmillan Publishing Company.

Han, A. F. 1987. Assessment of Transfer Penalty to bus Riders in Taipei: A Disaggregate Demand Modeling Approach. Transportation Research Record 1139: 8-14.

Heggie, I. G. 1976. A Diagnostic Survey of Urban Journey-to-Work Behaviour. Chapter 1 in Heggie, I.G. (ed.), Modal Choice and the Value of Travel Time. Oxford, England: Oxford University Press.

Henderson, C., and J. Billheimer. 1972. Manhattan Passenger Distribution Project: Effectiveness of Midtown Manhattan System Alternatives. Menlo Park, CA: Stanford Research Institute.

Hensher, D. A., and Q. Dalvi, Editors. 1978. Determinants of Travel Choice. Westmead, England: Saxon House.

Kocur, G., T. Adler, W. Hyman, and B. Aunet. 1982. Guide to Forecasting Travel Demand with Direct Utility Assessment. Resource Policy Center, Thayer School of Engineering, Dartmouth College, Hanover, $\mathrm{NH}$.

Le Squeren. 1991. Passenger Information. Advanced Telematics in Road Transport: Proceedings of the DRIVE Conference Brussels, February 1991, Vol. II. New York: Elsevier Science and Publishing Company, Inc.

Louviere, J. J. 1984. Using Discrete Choice Experiments and Multinomial Logit Choice Models to Forecast Trial in a Competitive Retail Environment: A Fast Food Restaurant Illustration. Journal of Retailing 60 (Winter): 81-107.

Louviere, J. J. 1988. Analyzing Decision Making: Metric Conjoint Analysis. Newbury Park, CA: Sage Publications.

Louviere, J. J., D. H. Henley, G. Woodworth, R. J. Meyer, I. P. Levin, J. W. Stoner, D. Curry, and D. A. Anderson. 1981. Laboratory-Simulation Versus Revealed-Preference Methods for Estimating Travel Demand Models. Transportation Research Record 794: 42-51.

Mackenzie, J. 1992. Evaluating Recreation Trip Attributes and Travel Time Via Conjoint Analysis. Journal of Leisure Research 24(2): 171-184. 
Meads, R. H. 1987. The Role of New Technology in Passenger Information Systems. 47th International Congress Lausanne, Part 6a. International Union of Public Transport, International Commission on Äutomation, Brussels.

Norman, K. L., and J. J. Louviere. 1974. Integration of Attributes in Bus Transportation: Two Modeling Approaches. Journal of Applied Psychology 59(6): 753-758.

Parker, B. R., and V. Srinivasan. 1976. A Consumer Preference Approach to the Planning of Rural Primary Health-Care Facilities. Operations Research 24(5): 991-1025.

Pickup, L., F. Kenny, A. Stathopoulos, V. Psaraki, G. Argyrakos, and K. Petrakis. 1990. Measuring the Potential Effects of Road Transport Informatics on Travel Patterns in European Cities. TSU Reference No. 549. Oxford University Transport Studies Unit, Oxford, England.

Reed, T. B. 1994. Waiting For Public Transit: The Utility of Real-Time Schedule Information. A dissertation submitted in partial fulfillment of the requirements for the degree of Doctor of Philosophy, Urban, Technological, and Environmental Planning: Sociotechnological Planning, in The University of Michigan, Ann Arbor, MI.

Rosko, M. D., M. DeVita, W. F. McKenna, and L. R. Walker. 1985. Strategic Marketing Applications of Conjoint Analysis: An HMO Perspective. Journal of Health Care Marketing 5(4): 27-38.

Solomon, K. M., R. J. Solomon, and J. S. Silien. 1968. Passenger Psychological Dynamics: Sources of Information on Urban Transportation, Report \#3. American Society of Civil Engineers and Journal of Urban Transportation Corporation, NY.

SPSS. 1990. SPSS Categories User Manual. SPSS, Inc., Chicago, IL.

Srinivasan, V., P. G. Flachsbart, J. S. Dajani, and R. G. Hartley. 1981. Forecasting the Effectiveness of Work-trip Gasoline Conservation Policies Through Conjoint Analysis. Journal of Marketing 45 (Summer): 157-172.

Stopher, P. R., B. D. Spear, and P. O. Sucher. 1974. Toward the Development of Measures of Convenience for Travel Modes. Transportation Research Record 527: 16-32.

Tarry, S., and L. Pickup. 1990. Public Transport Passenger Information Through New Telematics Technologies: A Review of Developments. TSU Reference No. 566. Oxford University Transport Studies Unit, Oxford, England.

Tull, D. S. and D. I. Hawkins. 1987. Marketing Research: Measurement and Method. New York: MacMillan.

Van Der Waard, J. 1988. The Relative Importance of Public Transport Trips-Time Attributes in Route Choice. Proceedings, PTRC Annual Meeting, London. 
Wachs, M. 1976. Consumer Attitudes Toward Transit Service: An Interpretive Review. Journal of the American Institute of Planners 421: 96-104.

Wilson, F. R. 1967. Journey to Work. MacLaren and Sons Ltd., London.

Wind, Y., and L. K. Spitz. 1976. Analytical Approach to Marketing Decisions in HealthCare Organizations. Operations Research 24(5): 973-990.

\section{About the Authors}

Thomas B. ReED is an Assistant Research Scientist in the Technology Planning and Evaluation Group, University of Michigan. Jonathan Levine is an Assistant Professor in the Urban and Regional Planning Program, University of Michigan. 


$$
\text { "to. }
$$

